\title{
DEVELOPER'S WILLINGNESS TO CONSTRUCT GREEN DWELLINGS IN CHINA: FACTORS AND STIMULATING POLICIES
}

\author{
Chenchen $\mathrm{HE}^{1 *}$, Xiaoming WANG ${ }^{2}$, Guochao ZHAO ${ }^{3}$ \\ ${ }^{1}$ School of Economics and Management, China University of Geosciences, Wuhan, China \\ ${ }^{2}$ School of Civil Engineering and Mechanics, Huazhong University of Science and Technology, \\ Wuhan, China \\ ${ }^{3}$ School of Economics and Management, Zhejiang University of Technology, Hangzhou, China
}

Received 18 January 2018; accepted 13 June 2018

\begin{abstract}
Green dwelling (GD) is a way to mitigate impacts of the building stock on environment and provide a better living condition for residences. However, the number of GDs is relatively small. Especially in China, GDs only account for less than $0.4 \%$ of the total buildings. It is directly due to the shortage of supply, which is influenced by the lack of willingness to develop. To stimulate the GD diffusion, the study applies structural equation model to analyse the factors in developers' willingness to construct GDs, considering the inter-relationships and relative influences among factors. Further, it calculates the influence of each policy and policy subseries on developers' willingness. It is showed that developers' willingness is mostly influenced by their developing ability, followed by market development. Then comes government policy and corporate responsibility. In terms of stimulating policies on developers' willingness, floor-to-area density award is of the biggest impact, followed by the green building requirement and interest rare. As to the policy subseries, mandatory requirements has larger effects on developers then voluntary incentives. Besides, in China, developers are more sensitive to financial incentives than non-financial ones. Accordingly, suggestions for policy making are proposed to stimulate developers to construct GDs.
\end{abstract}

Keywords: developer, green dwelling, willingness to construct, factor, stimulating policy, structural equation model.

\section{Introduction}

The global climate change uncovers the overuse of energy and the destruction of environment. The construction industry and particularly the residential sector has been responsible for the issue (He et al. 2017). According to the World Business Council for Sustainable Development, building block accounts for $40 \%$ of total energy consumption, while the residential sector accounts for more than half of that (Zuo, Zhao 2014; Zhang 2015). Except for energy consumption, construction industry also emits lots of greenhouse gas (GHG). It is reported that carbon emissions of buildings across the world will reach 42.4 billion tonnes in 2035 (USEIA 2010). Under the circumstance, the green economy is taken as a long-term strategy by many countries. It boosts the economic growth along a sustainable path and protects the environment from further deterioration (Yi, Liu 2015). In response to climate change and develop a green economy, a green revolution is happening in the building sector (Gou et al. 2013).
Green dwelling (GD), as a branch of green building (GB), aims at minimizing the influence on environment during life cycle and providing a comfortable residential environment (Gabay et al. 2014). Recently, many countries have made efforts to diffuse GDs. They have set a series of policies on GDs and awarded green labels to buildings meeting the standard. In this paper, we mainly study on the dwellings with green labels. In spite of the effort of the countries, the number of GDs in the market is still small. In China, GDs only account for less than $0.4 \%$ of the total buildings. It is directly due to the shortage of supply, which is influenced by the lack of willingness to develop GDs. Thus, understanding the factors in developer's willingness to enter the GD market and their preference to stimulating policies helps to improve GD market from perspective of suppliers.

There are many studies on factors in GD developing (Elias, Lin 2015; Qian et al. 2015; Chegut et al. 2014).

*Corresponding author. E-mail: mofare@163.com 
Although "green price premiums" accompany the development of green buildings (Deng, Wu 2014), the cost related problem has been showed as the paramount obstacle (Qian et al. 2015). It is because that the developers bear the cost premium while most of the benefits generated from the green building is primarily revealed during operation (Hwang, Tan 2012). In addition, the lack of awareness about the benefits of GD also decrease developer's willingness (Patel, Chugan 2013). The developing of GD brings not only economic profits but also corporate reputation for the developers (Xu et al. 2013; Olubunmi et al. 2016). However, many developers have not realized that. Moreover, it is showed that the corporate social responsibility and developing ability also influence developers' decision on GD (Hui et al. 2016). While many companies search for economic profit, there are some others focus on building social value because that they have a higher level of corporate social responsibility (Prakash 2000; Porter, Kramer 2006). It is also showed that most of the existing GD in the market are mainly developed by developers with large scale and strong ability (Zhang, Liu 2013). Since GD development needs much capital and many green technologies, developers lacking of ability are prevented from entering GD market. Besides, since the demand in market is still not sufficient, the developers hesitate to enter the GD market to avoid risk. However, most of the recent studies only discuss the factors independently, while actually they may be interacted. According to the theory of planned behaviour, there are interactions among the ability of a person, his attitude and subjective norm (Ajzen 1985). Moreover, the policy can improve the developers' ability by technical support and education (Gulen, Ion 2016). Thus, there might be interactions among the factors in developers' willingness, such as the interrelationships among developer's social responsibility, perception of benefit, their developing ability and other factors.

As to the policies on developers, many studies analyse the importance and classification of policies (Elias, Lin 2015; Olubunmi et al. 2016; Liu et al. 2014; Shazmin et al. 2016). However, different policies have various influences on developers, while only a few studies piecemeal discuss the specific influence of each policy to developers. As to the financial and non-financial incentives, Zhou (2015) found that compared to subsidies, developers are more sensitive to non-financial incentives, including permitted floor space/land ratio and land allocation priority. Because these two incentives can bring economic benefit since developers could build more buildings on the limited land, while the subsidies would not end up with much money after vanishing in the different layers of government. There is also study finding that the expedited permitting to be more significant than subsidies. Since it could save developers' time by mitigating risk and process issues (Choi 2009). The time saving could lead to project cost reduction for developers. Matisoff et al. (2016) indicate that the voluntary policies such as pigovian taxes and subsidies are more cost effective to stimulate developers than the command-and-control approaches. However, there are a lack of a comprehensive analysis on developers' reactions to different policies. Such as how can the voluntary and mandatory policies impact developers. Further, what are the detailed influence of each specific policy on developers' willingness.

In light of the recent research gap, the paper assumes that there are relationships among the factors in developer's willingness. It applies the structural equation model to analyse the inter-relationships among the factors and finds the effects on developers' willingness. Moreover, it further researches on the influences of specific policies on developers. Thus, the paper not only provides a better understanding of the factors affecting developer's decision on GDs, but it also offers valuable suggestions for government policy making.

\section{The factors in developers' willingness}

\subsection{The developing ability}

Developing abilities have influences on developers' willingness to construct GDs. Since GD development adopts certain green technologies and has a premium cost, most of the GD developers are of a strong ability (Deng, Wu 2014). They have sufficient funds to invest in developing GDs and abilities to research green related technology. Moreover, the company with higher ability has more skilled employees who can do better jobs on GD development. According to the theory of planned behaviour, perceived behaviour control is related to a person's intention (Ajzen 2011). The developing ability explains how much control a developer has over GD development, thus shows a positive effect on his' willingness to enter the GD market.

\subsection{Corporate responsibility}

Corporate responsibility means a company's attitude toward environmental protection and social development. The company with a higher corporate responsibility will feel a stronger obligation to mitigate environmental problems and accelerate social development. Thus, he will carry out environmental and social friendly activities, which are based on the enterprise culture and corporate policies (Sweeney 2006). Since GD helps reduce energy and materials consumption and create a better residential environment, the developer has a higher corporate responsibility will be more likely to develop GDs (Hui et al. 2016).

\subsection{GD market development}

The developers' decision depends a lot on the current GD market. They better the current market situation is, the more optimistic the developers would be, and the more they want to enter the market. The GD market development is mainly represented by three elements: the current demand, competition and the price premium of GDs (Zhang et al. 2011). When the demand is sufficient, the developer will face less risk of unsalable GDs, thus they 


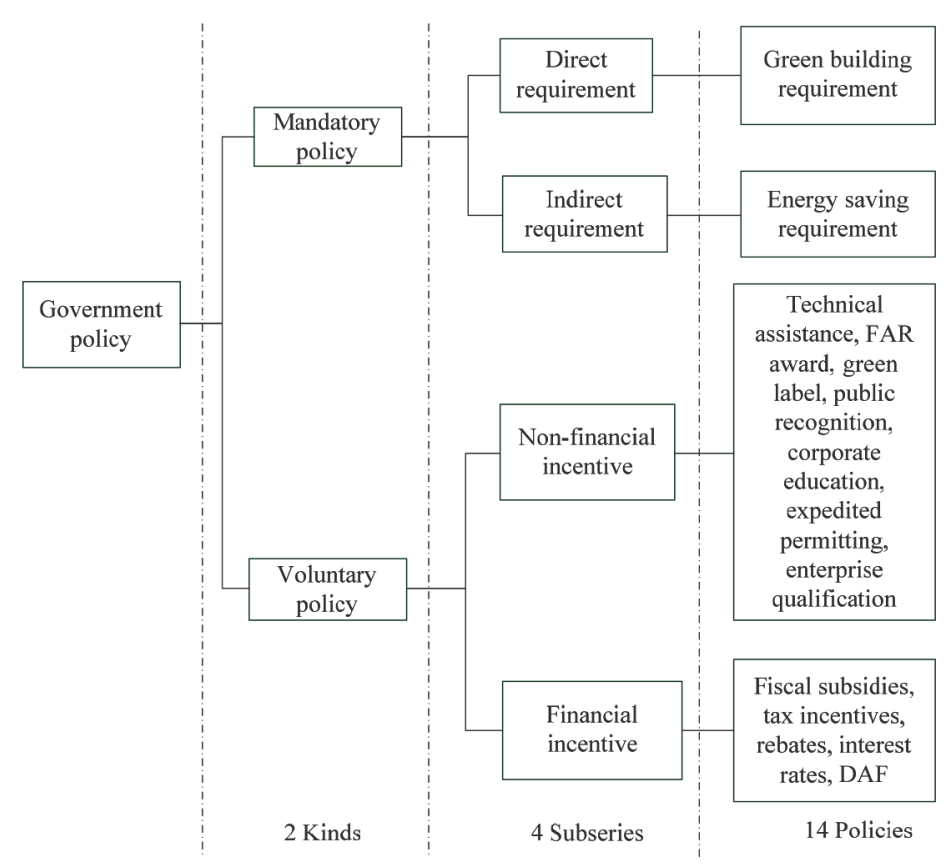

Figure 1. Classification of government policy

will show more interest in developing GDs. Besides, the more competitive the current market is, the less the developers are willing to enter green dwelling market. In terms of current GD price premium in market, a higher price premium shows a better market acceptance and economic potential. Thus, the developers' willingness will increase as the current price premium goes up.

\subsection{The perception of GD's benefit}

The perception of GD's benefit explains what developers gain from GD. The developers' expected benefit from GDs will affect their decision on developing. The larger the benefit is, the more eager they are to develop GDs. The benefits of GDs mainly contain the expected economic benefit, company reputation and customer attention. The GDs bring with economic benefit in the long term. The cost of GDs may be higher than conventional dwellings. However, the expected premium price and the benefit in operation period will offset the incremental cost and provide economic earnings for developers (Zheng et al. 2012). Moreover, the development of GDs helps to create a good corporate image with social responsibility (Xu et al. 2013; Eichholtz et al. 2010). It is an intangible asset for a company (Olubunmi et al. 2016). In addition, the coverage of GD and the publicity of green building labelling projects bring companies with consumer attention.

\subsection{The government policy}

Because of the positive externalities of GD, it is necessary for the participation of the government. It provides incentives promoting developer's desire to enter GD market. According to references, we divide the policies into two kinds: mandatory and voluntary ones (Matisoff et al.
2016). The mandatory policies mainly include the direct and indirect requirements. For instance, the Chinese government requires that the residential community over 0.2 million square meters and all affordable houses should apply for green building labels. It is a direct requirement mandating GB standards for a particular sector. There are also indirectly policies on GD development, such as the energy-saving standard. Chinese government mandates the energy usage to be $50-65 \%$ more efficient than the basic standard of the 1980s (Zhou 2015). As the GD is an important way in respond to energy conservation requirements, many developers choose to develop GDs.

In term of the voluntary incentives, they include the non-financial and financial ones. Financial incentives refer to the policies related with money. These contain fiscal subsidies, tax incentives, rebates, interest rates and discounted development application fees (DAF) (Liu, Xu 2015; Shapiro 2011). On the other hand, the non-financial incentives have no relationship to money. These consist of technical assistance, floor-to-area density (FAR) award, green label, public recognition, corporate education, expedited permitting and enterprise qualification (Sentman et al. 2008). Various policies have different effects on behaviour of developers. In total, there are two kinds of government policies: mandatory and voluntary ones. These further include four subseries and 14 detailed policies (Figure 1).

\subsection{Hypothesis}

According to the factors in willingness to develop GDs, we propose 10 hypotheses. Table 1 lists the latent variables and their indicators. Figure 2 shows a conceptual diagram containing the major hypotheses. Table 2 lists all the hypotheses formulated prior to the path model development and the references. 
Table 1. Latent variables and their indicators

\begin{tabular}{|c|c|c|c|}
\hline Latent variable & Symbol & Indicators & References \\
\hline \multirow[t]{4}{*}{ Developing ability } & NL1 & Manpower and resources & Wu, S. I. and Wu, Y. C. (2014) \\
\hline & NL2 & Development capital & Wu, S. I. and Wu, Y. C. (2014) \\
\hline & NL3 & Technical development & Wu, S. I. and Wu, Y. C. (2014) \\
\hline & NL4 & Green dwelling development experience & Li et al. (2014) \\
\hline \multirow[t]{4}{*}{$\begin{array}{l}\text { Corporate } \\
\text { responsibility }\end{array}$} & ZR1 & Environmental cognition & $\begin{array}{l}\text { Wymer and Polonsky (2015), Wu, S. I. and Wu, Y. C. } \\
\text { (2014) }\end{array}$ \\
\hline & ZR2 & Social awareness & Choi (2010), Abidin (2010) \\
\hline & ZR3 & Green corporate culture & Xu and Qiu (2006) \\
\hline & ZR4 & Clarity of responsibility and accountability & Timperley (2008) \\
\hline \multirow{3}{*}{$\begin{array}{l}\text { Market } \\
\text { development }\end{array}$} & SC1 & Market competition & Zhang et al. (2011) \\
\hline & SC2 & Consumers Acceptance & Windapo (2014) \\
\hline & SC3 & Price of green dwelling & Chegut et al. (2014) \\
\hline \multirow{4}{*}{$\begin{array}{l}\text { Perception of } \\
\text { benefit }\end{array}$} & $\mathrm{RZ1}$ & Goodwill benefit & Wu, S. I. and Wu, Y. C. (2014), Wang et al. (2015) \\
\hline & RZ2 & Economic benefit & Wymer and Polonsky (2015) \\
\hline & RZ3 & Environmental benefit & Carnoske et al. (2010) \\
\hline & RZ4 & Attention benefits & Wu, S. I. and Wu, Y. C. (2014) \\
\hline \multirow{4}{*}{$\begin{array}{l}\text { Government } \\
\text { policy }\end{array}$} & $\mathrm{ZC1}$ & Financial voluntary incentive & Olubunmi et al. (2016) \\
\hline & $\mathrm{ZC} 2$ & Non- financial voluntary incentive & Olubunmi et al. (2016) \\
\hline & ZC3 & Indirect compulsory policy & Zhou (2015) \\
\hline & ZC4 & Direct compulsory policy & Zhou (2015) \\
\hline \multirow{3}{*}{$\begin{array}{l}\text { Willingness to } \\
\text { develop green } \\
\text { dwellings }\end{array}$} & YY1 & Developing proportion of green dwellings & Ma and Wang (2012) \\
\hline & YY2 & Investment on green technology & Wang and Liu (2014) \\
\hline & YY3 & Green dwelling promotion funding & Theunissen (2016) \\
\hline
\end{tabular}

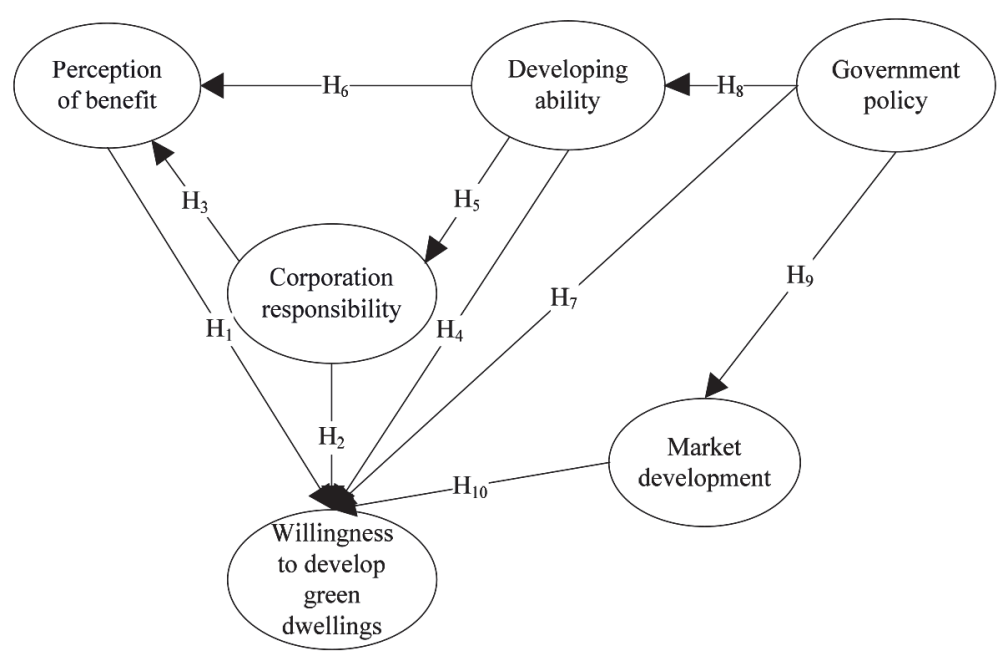

Figure 2. Hypothetic relationship between latent variables

\section{Methodology}

\subsection{Questionnaire design}

Questionnaire surveys were designed to elicit developers' decision on GDs, including the factors in their willingness to develop GDs and the influence of policies on their decisions. It included three parts. The first part were questions about respondents' company and their social demographics. In part 2, we analysed the factors in developers' willingness to enter GD market. Each factor included three or four questions according to the indicators, developers were asked to rate on a 5-point verbal scale (from 1 to 5 , where ' 1 ' stands for 'strongly disagree' and ' 5 ' means 'strongly agree') on statements relating to the factors. 
Table 2. Hypotheses and references

\begin{tabular}{|c|c|c|c|}
\hline Hypothesis & & Path & References \\
\hline $\mathrm{H} 1$ & Perception of benefit $\rightarrow$ & Willingness to develop green dwellings & Patel and Chugan (2013) \\
\hline $\begin{array}{l}\mathrm{H} 2 \\
\mathrm{H} 3\end{array}$ & Corporate responsibility $\rightarrow$ & $\begin{array}{l}\text { Willingness to develop green dwellings } \\
\text { Perception of benefit }\end{array}$ & $\begin{array}{l}\text { Ajzen (2011) } \\
\text { Ajzen (2011) }\end{array}$ \\
\hline $\begin{array}{l}\mathrm{H} 4 \\
\mathrm{H} 5 \\
\mathrm{H} 6\end{array}$ & Developing ability $\rightarrow$ & $\begin{array}{l}\text { Willingness to develop green dwellings } \\
\text { Corporate responsibility } \\
\text { Perception of benefit }\end{array}$ & $\begin{array}{l}\text { Ajzen (2011) } \\
\text { Berens et al. (2007) } \\
\text { Sert (2012) }\end{array}$ \\
\hline $\begin{array}{l}\text { H7 } \\
\text { H8 } \\
\text { H9 } \\
\text { H10 }\end{array}$ & $\begin{array}{l}\text { Government policy } \rightarrow \\
\text { Market development } \rightarrow\end{array}$ & $\begin{array}{l}\text { Willingness to develop green dwellings } \\
\text { Developing ability } \\
\text { Market development } \\
\text { Willingness to develop green dwellings }\end{array}$ & $\begin{array}{l}\text { Windapo (2014) } \\
\text { Gulen and Ion (2016) } \\
\text { Matisoff et al. (2016) } \\
\text { Chegut et al. (2014) }\end{array}$ \\
\hline
\end{tabular}

Finally, part 3 intended to understand specific influences of different policies on developers. As analysed in Section 1.5 , there are 14 policies on GD development. We asked the respondents to rate the influence of each policy on their willingness to develop GDs from 1 to 5 (' 1 ' stands for 'very weak' and ' 5 ' represents 'very strong'). In total, there were 40 questions in the survey, including 4 questions in part one, 22 questions in part two and 14 questions in part three. Before the formal survey, we had asked 20 developers to do the survey and provide suggestions to make the statement of each question more representative and easy to understand.

\subsection{Data collection and analysis}

We collected data by online questionnaire surveys and the targets were the managers of the company. Recently, the total number of developer companies is 94948 in China. To better represent the situation of current developers, we consulted the comprehensive strength ranking of developers in China (CREAC 2017). We chose the developers ranked the top 100, the middle 100 and the bottom 100 . They were sent an e-mail including the purpose of the survey and a link to the questionnaire to the managers. The e-mail also asked them to fill in the questionnaires whine one week. As to the developers who did not answer on time, we conducted a second e-mail to them again. Finally, 246 questionnaires were collected among which 211 were valid. The effective rate was $85.7 \%$ with the sample fraction of $0.22 \%$.

The factors in developer's willingness was analysed by structural equation model (SEM), which is a hybrid of factor analysis and path analysis (Weston, Gore 2006) $<1$ Cite $></$ EndNote $>$. It is used to reveal the relationships between latent variables and indicators, and the casual relationships among dependent variables and between dependent and independent variables (Bentler, Weeks $1980)</$ Cite $></$ EndNote $>$. Thus, the method is suitable to reveal the multi-lateral relationships among factors investigated in this study. Based on SEM, we could further get the direct, indirect and total effect of factors in developers' willingness (Kline 2016). As to the influences of specific policies, we calculated the scores based on their impact degrees. The larger the score was, the bigger impact was. Besides, the effects of subseries were analysed according to the proportion of respondents who ranked each subseries as different degrees.

\section{Results}

\subsection{Respondents' characteristics}

The social-demographic of respondents are shown in Table 3. There are $72.04 \%$ male, and most of the respondents are aged 21-30. As to the education, about $61.14 \%$ of the respondents are master; about one-third is bachelor. In terms of income, half of them have a monthly income from 3001 to $6000 \mathrm{RMB}$; while more than one-third earns 6001-9000 RMB every month.

Table 3. Characteristics of respondents $(\mathrm{N}=211)$

\begin{tabular}{|l|l|}
\hline \multicolumn{1}{|c|}{ Characteristics } & Number (Percentage) \\
\hline Gender & \\
\hline Male & $152(72.04)$ \\
Female & $59(27.96)$ \\
\hline Age & \\
\hline $21-30$ & $158(74.88)$ \\
$31-40$ & $42(19.91)$ \\
$41-50$ & $11(5.21)$ \\
\hline Education & \\
\hline High school or lower & $8(3.79)$ \\
Bachelor & $63(29.86)$ \\
Master & $129(61.14)$ \\
Doctor & $11(5.21)$ \\
\hline Personal Monthly income (RMB) & \\
\hline$\leq 3000$ & $6(2.84)$ \\
$3001-6000$ & $80(37.92)$ \\
$6001-9000$ & $107(50.71)$ \\
$>9000$ & $18(8.53)$ \\
\hline
\end{tabular}




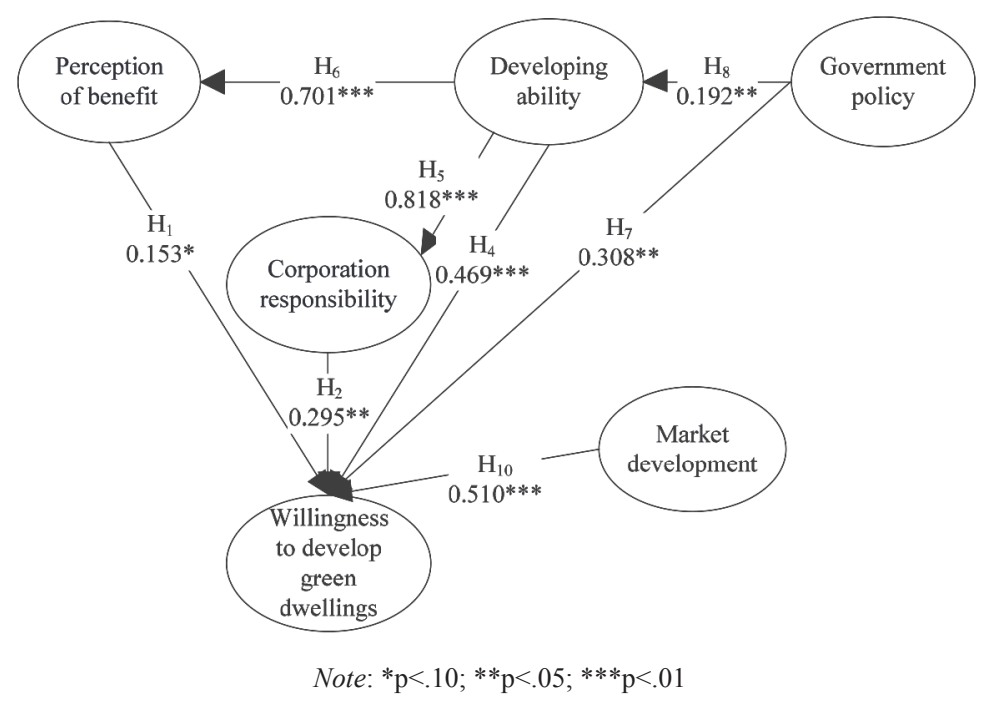

Figure 3. Relationships between latent variables

Table 4. The effect of observed variable on latent variable

\begin{tabular}{|c|c|c|}
\hline Latent variable & Observed variable & Effect \\
\hline \multirow[t]{4}{*}{ Developing ability } & Manpower and resources & $0.840^{\star * *}$ \\
\hline & Development capital & $0.869^{* * *}$ \\
\hline & Technical development & $0.909^{* * *}$ \\
\hline & Green dwelling development experience & $0.879^{* * *}$ \\
\hline \multirow[t]{4}{*}{ Corporate responsibility } & Environmental cognition & $0.750^{* * *}$ \\
\hline & Social awareness & $0.806^{* * *}$ \\
\hline & Green corporate culture & $0.885^{\star * *}$ \\
\hline & Clarity of responsibility and accountability & $0.799^{* * *}$ \\
\hline \multirow{4}{*}{ Perception of benefit } & Goodwill benefit & $0.733^{\star * *}$ \\
\hline & Economic benefit & $0.725^{\star *}$ \\
\hline & Environmental benefit & $0.618^{\star *}$ \\
\hline & Attention benefits & $0.655^{\star * *}$ \\
\hline \multirow[t]{4}{*}{ Government policy } & Direct requirement & $0.858^{\star * *}$ \\
\hline & Indirect requirement & $0.823^{* * *}$ \\
\hline & Financial incentive & $0.818^{\star * *}$ \\
\hline & Non- financial incentive & $0.628^{\star * *}$ \\
\hline \multirow[t]{3}{*}{ Market development } & Market competition & $-0.634^{* *}$ \\
\hline & Consumers Acceptance & $0.740^{* * *}$ \\
\hline & Price of green dwelling & $0.808^{\star * *}$ \\
\hline \multirow{3}{*}{$\begin{array}{l}\text { Willingness to develop green } \\
\text { dwellings }\end{array}$} & Development of green dwellings & $0.874^{* * *}$ \\
\hline & Investment on green technology & $0.952^{\star * *}$ \\
\hline & Green dwelling promotion funding & $0.868^{* * *}$ \\
\hline
\end{tabular}

Note: ${ }^{*} \mathrm{p}<.10 ;{ }^{* *} \mathrm{p}<.05 ;{ }^{* * *} \mathrm{p}<.01$

\subsection{Factors in willingness}

The interactions between factors and their effect on willingness are shown in Figure 3. The effects of observed variables on latent variables are shown in Table 4 . The relationships between latent variables and observed vari- ables are included in the models only after they have been verified by reliability analysis and validity analysis. The goodness of fit is shown in Table 5, and all the calculated values meet the acceptance criteria. 
As shown in Figure 3, the hypothesis verified are H1, H2, H4, H5, H6, H8, H9, H10. Further, the standardized casual relationships between latent variables are also shown as the values beside the line. The larger the value is, the bigger the influence is. It is found that the willingness to develop GDs is determined by perception of benefit $(\beta=0.153)$, corporation responsibility $(\beta=0.295)$, developing ability $(\beta=0.469)$, government policy $(\beta=0.308)$ and market development $(\beta=0.510)$. Among which market development has the largest direct influence, then comes the developing ability and government policy. While perception of benefit is with the least direct influence. In addition, the developing ability also has relationships with the perception of benefit and corporation responsibility, which further provide indirect effect on developers' willingness. The government policy also has an indirect influence on developer willingness via impacts on their abilities.

In sum, the direct, indirect and total effects are shown in Table 6. In terms of total effect, the developing ability is the paramount factor in developer's GD decision $(\beta=0.818)$. It is in line with current market situation in China. Most of the recent GDs are developed by the leading developers with strong abilities, such as Vanke, Wanda, MOMA, and LVDI (Zhou 2015). Furthermore, as we can see in Table 4, developer's ability is mainly indicated by their technical development $(\beta=0.909)$ and green related experience $(\beta=0.879)$. Since the GD development needs to apply green related technologies and management tools, the developer's technical support and experience improve could represent their ability to develop GDs. The second biggest influence is market development. It only has a direct effect on developers' willingness. Every improvement in market would lead to 0.51 increase in developing willingness. Besides, market development could be improved if less market competition $(\beta=-0.634)$, more consumers acceptance $(\beta=0.470)$ and higher price of GDs $(\beta=0.808)$ were perceived in GD market. The third biggest factor affecting developers' willingness is government policy.
When government policy goes up by 1 standard deviation, the willingness goes up by 0.465 totally. The impact is caused by both direct and indirect effects. The government policy has a direct effect with $\beta=0.308$. The indirect effect improves developer's ability, which further influence their willingness $(\beta=0.157)$. The government policy is represented by four observed variables, among which direct requirement is of the highest factor loader $(\beta=0.858)$, then comes the indirect requirement with $\beta=0.823$. The fourth biggest factor on willingness is corporate responsibility, with the total effect of 0.295 . The higher the corporate responsibility is (especially green corporate culture and social awareness), the more developers want to develop GDs. The perception of benefit turns out to have the least effect on developer's willingness $(\beta=0.153)$. The more benefit the developers think about GD, the more eager they are to develop GDs. This variable is mainly measured by the goodwill benefit $(\beta=0.733)$ and economic benefit $(\beta=0.725)$.

\subsection{Preference for stimulating policies}

According to the analysis above, government policy is of the third biggest influence on developer's willingness, except for developing ability and market development. Since the Chinese GD market is in the initial stage that most of the developers only have a low ability and the market is unmatured, it is essential for government simulations. However, there are only a few studies on effects of each policy. Therefore, we calculate the influence of each policy detailly in this section.

The influence of each policy is shown in Figure 4. In general, most of the respondents think the policies have an average or a strong effect on them. It means that the policies are more or less able to influence developers' decisions. As shown in Figure 4, technical assistance, enterprise qualification, corporate education and expedited permitting are mainly regarded as of average impacts, while other 10 policies are of strong impacts on most

Table 5. Acceptance criteria and calculated values of various goodness-to-fit indices

\begin{tabular}{|lcccc|}
\hline \multicolumn{1}{|c}{ Goodness of fit index } & $\mathrm{X}^{2} / \mathrm{df}$ & $\begin{array}{c}\text { Standard root mean } \\
\text { square residual } \\
\text { (SRMR) }\end{array}$ & $\begin{array}{c}\text { Root mean square } \\
\text { error approx. } \\
\text { (RMSEA) }\end{array}$ & $\begin{array}{c}\text { Comparative fix index } \\
\text { (CFI) }\end{array}$ \\
\hline Acceptance criteria & $2.0-5.0$ & $\leq 0.090$ & $\leq 0.080$ & $\geq 0.960$ \\
Calculated value & 2.546 & 0.0626 & 0.059 & 0.963 \\
\hline
\end{tabular}

Table 6. Effect on willingness to develop GDs

\begin{tabular}{|lccc|}
\hline \multicolumn{1}{|c}{ Factors } & Direct effect & Indirect effect & Total effect \\
\hline Perception of benefit & 0.153 & 0 & 0.153 \\
Corporate responsibility & 0.295 & 0 & 0.295 \\
Developing ability & 0.469 & 0.349 & 0.818 \\
Government policy & 0.308 & 0.157 & 0.465 \\
Market development & 0.510 & 0 & 0.510 \\
\hline
\end{tabular}




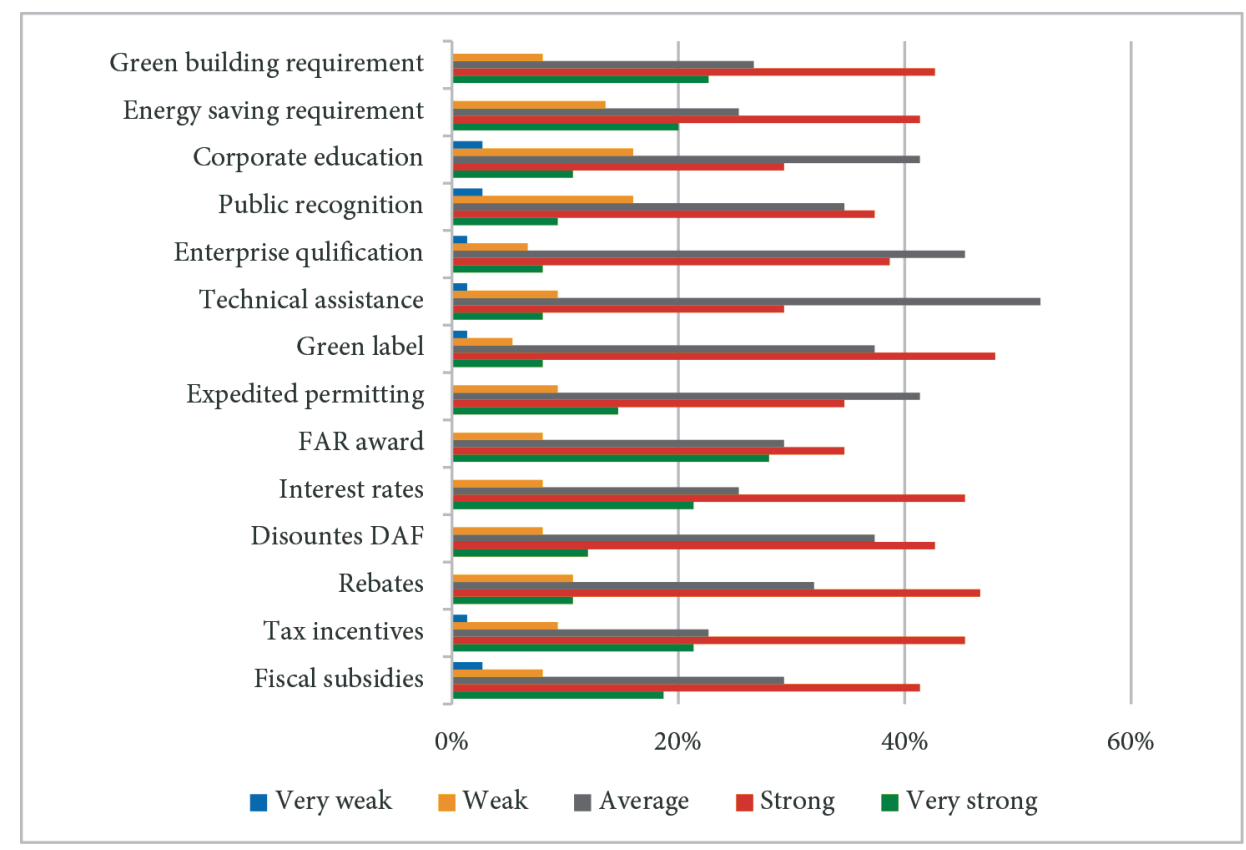

Figure 4. The percentage of each policy chosen as different degree of influence

developers. In terms of the proportion that a policy chosen as a very strong influence, $28 \%$ of the respondents think that FAR award has a very strong influence on their decisions. Besides, green building requirement are viewed as a strong impact by $22.67 \%$ of the interviewees. There are also $21.33 \%$ of the respondents think tax incentives and interest rates are of very strong impacts on them. Besides, about half of the participants think that green label is a stimulation strongly affecting their willingness to develop GDs. In addition, there are also $45.33 \%$ of the respondents regarding interest rate as a strong impact on developer decision. As to the proportion that a policy perceived as average influence, $53 \%$ and $45.33 \%$ of the respondents think that technical assistance and enterprise qualification are of average influences respectively. Moreover, the public recognition and corporate education are perceived to have only weak effects on developers' willingness by $16 \%$ of those polled. To count the overall impact of each policy, we score the policies according to their degree of influence. From very strong to very weak influence, the policies score 5,4,3,2,1 respectively. We used the proportion of each score as its weight. The proportion was used instead of simply the number of people to get a standardized

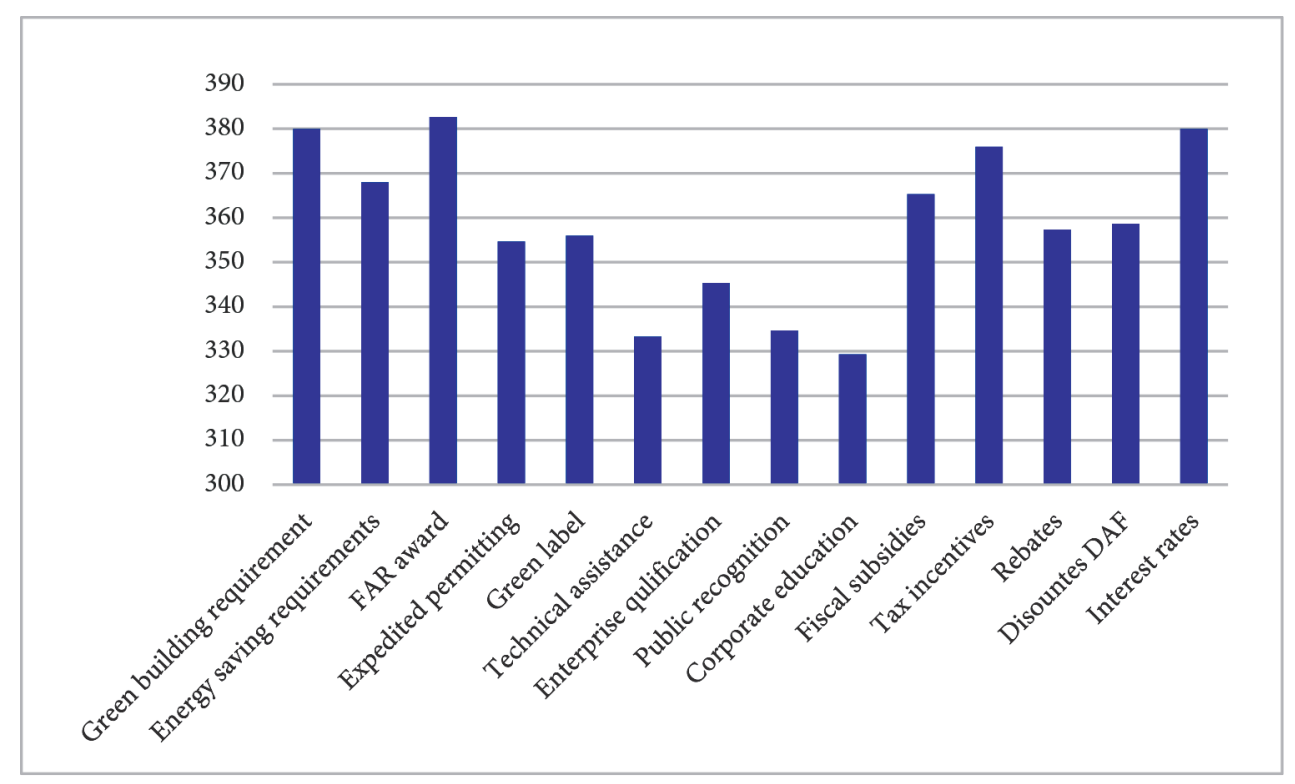

Figure 5. The overall score of policies 
result. Thus, the overall score for each policy is calculated as follows:

$$
F_{j}=\sum_{i=1}^{5} p_{i j} \times i \times 100,
$$

where: $i$ - the score of different degrees of influence; $j$ the number of policy, $j=1,2,3, \ldots, 13,14 ; F_{j}$ - the overall score of the $j^{\text {th }}$ policy; $p_{i j}$ - the proportion of the respondents who regard $j^{\text {th }}$ policy as scoring $i(\%)$.

It is shown in Figure 5 that the maximum impact on developer's willingness is the FAR reward and the score is 382.67. Then comes the green building requirement and interest rate, scored 380 and 379.96, respectively. In addition, financial incentives such as tax incentives and fiscal subsidies also improve developers' willingness, with the score of 375.97 and 365.33. In contrast, the non-financial policies have lower scores. Technical assistance, public recognition and corporate education only have scores less than 335 . To analyse the total influence of four policy subseries, we calculate the percentage of respondents who choose the policy subseries as different degree of influence (Figure 6). It is showed that the direct requirement has the strongest influence on developers' willingness. There are $22.67 \%$ of the respondents regarding it as a very strong effect, and $42.67 \%$ viewing it as a strong influence. The indirect requirement has the second largest influence. Then comes the financial incentive, with a strong effect on $44.27 \%$ of the respondents and an average effect on $29.33 \%$ of the respondents. The subseries with the minimal impact is non-financial incentive, which is regarded with an average influence by nearly half of the respondents (40\%). The results are in accordance with the SEM model that the impact loads of direct requirement, indirect requirement, financial incentive and non-financial incentive are valued from the largest to the smallest.

\section{Discussion}

Among the five factors in developers' willingness, developing ability has the largest effects, since it has a direct effect and indirect effects via corporate responsibility and perception of benefit. Developers with higher development abilities have more manpower, capital, technology and GD experience to meet the development needs of GDs. Besides, the higher developing ability is, the larger corporate responsibility and more benefit the developer may percept, which further improve their willingness to develop GDs. Thus, at the primary stage of GD market growth, it is more likely for the developers with high abilities to act as leading enterprises in GD development. From the perspective of the governments, they should help to improve developers' ability by providing technical assistance, corporate education and enterprise qualification. In this way, they could further increase developers' willingness to develop GDs.

In addition, the market development is the second largest effect on developers' willingness. The developers care a lot about the market competition, consumer's acceptance and price of GD. Only when they think the market development is mature enough, will they be eager to enter the GD market. As to the influence of policies on developers' willingness, it ranks the third after market development. The direct impact of policies is 0.308 , and it also has an indirect effect via improving developing ability. Thus, government policy is an important stimulation to promote the willingness of developers. Especially when the market is not mature enough, the government policy becomes crucial to stimulate developers. The last two factors affecting developers are corporate responsibility and perception of benefit. Accordingly, in the initial stage when there are only a few developers constructing GDs,

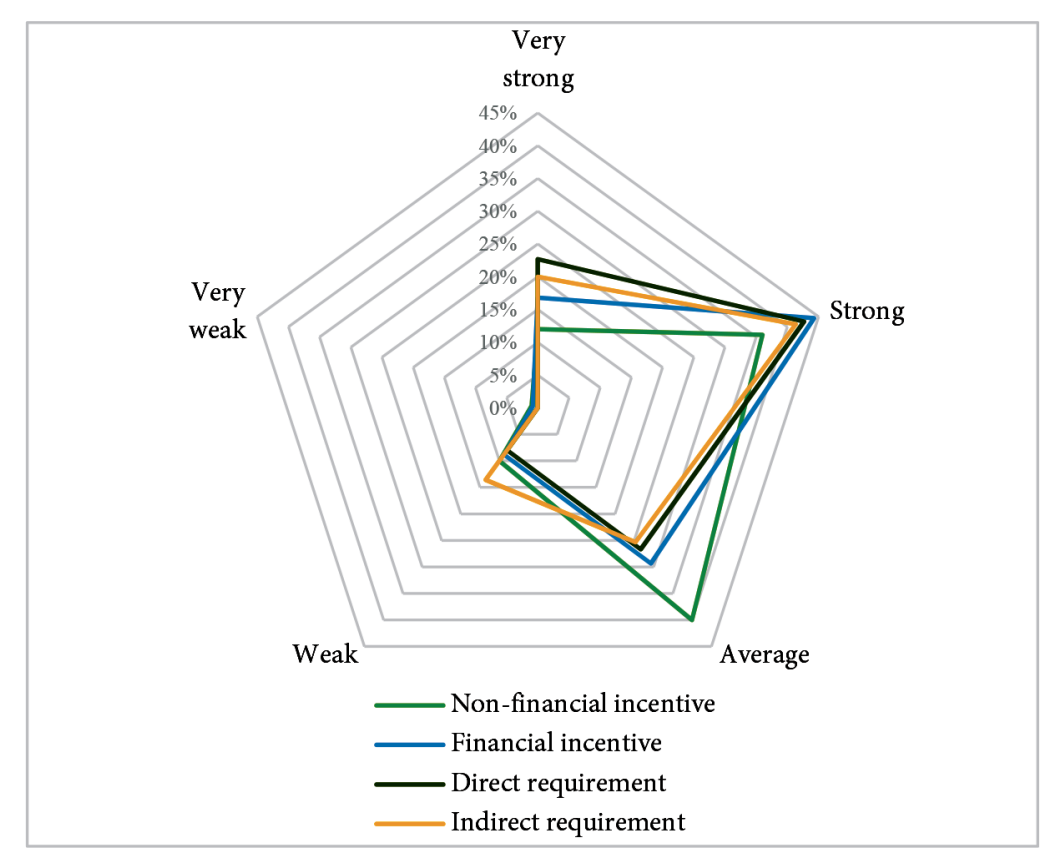

Figure 6. Impact degree of policy subseries 
the government could preferentially provide stimulations to developers with high corporate responsibility. Moreover, to improve the developers' perception of benefit, the government could apply some new incentives, such as encouraging developers to undertake the responsibility of GD operation. Thus, the developers could get more benefit from operating stage.

Regarding the influence of each policy subseries, it is found that the directly mandatory GB requirements are of the biggest influences. And then comes indirectly mandatory requirements. Since the mandatory requirements stipulate the compulsory behaviours for developers, it can mostly affect developers compared with other policies. Thus, it is most efficient to mandate the GB and related requirement for specific dwellings. Recently, a number of developed countries have begun to take some mandatory measures. However, it is more general to apply voluntary incentives in China, considering the primitive development situation of GDs. Currently, GDs only account for less than $0.4 \%$ of the total buildings in China, and the developers' abilities are not that high. Thus, the recent condition is not mature to mandate a GD requirement in most of the dwellings in China (Liu, Xu 2015). It is more suitable to apply the voluntary policies at this stage in major provinces of China.

In terms of the voluntary policies, the current developers in China are more sensitive to financial incentives than non-financial ones, especially to lowering the interest rate and tax incentives. It is not consistent with the conclusions of some studies, which show that the non-financial incentives have a more significant impact on the adoption of GD than financial incentives (Olubunmi et al. 2016; Choi 2010). However, those studies are all based on surveys in the United States, while in China, it is not the case. It might because that in China, developers would more prefer direct economic benefits.

As to the non-financial incentives, the influence degrees are relatively low, except for FAR award. FAR award is scored as the largest influence on developers, even larger than other financial incentives. It allows developers to achieve a larger building area on the same area of land, which provide more economic benefits indirectly. However, it is not widely spread in China. It is because that the FAR is controlled by the local planning bureau, while the green building is controlled by local housing bureau. The gap between the bureaus limits the policy implementation. Thus, other non-financial incentives are more popular in China, among which the green label and expedited permitting have relatively higher influences, scored around 355.

In conclusion, to stimulate developers to enter GD market, the government should consider the factors in developers' willingness. The government could provide technical support and corporate education to improve developers' ability, which further influence developers' willingness. Moreover, the market developing should also be considered. At the primitive stage of GD market in China, the government should provide more voluntary incentives to developers. While the mandatory requirement could be implemented in some province with better economic and social development. As to the specific policies, the FAR award is of the largest influence. However, it is hindered by the gap between housing bureau and planning bureau in China. Thus, it is essential to strengthen the interaction and cooperation between the bureaus and make a reasonable FAR incentive for developers. Except for FAR award, the financial incentives are the most suitable policies in China currently. Among which interest rate, tax incentives and fiscal subsidies are of the largest influence. Accordingly, the government could apply the most efficient policies according to the factors in developers' willingness and influence of different policies.

\section{Conclusions}

The paper has analysed the factors in developers' willingness to develop GDs. Structural equation model is used considering the inter-relationships among the factors. Moreover, the paper further calculated the influence of every government policy and subseries on developers' willingness. It shows that the developers' willingness is impacted by developing ability, market development, government policy, corporation responsibility and perception of benefit (ordered from the biggest impact to the smallest). It is also found that developers are more attracted by financial incentives then non-financial ones in China. The findings in this paper is useful for the government to make reasonable policies. In addition, the method proposed could also be applied in other places. Since the limitation of time and expenditure, we only analysed a small group of developers in China. In further work, it would be ideal to carry out a more comprehensive study with a larger pool of developers. More factors including economic and social development could also be considered. It could also be possible to make a more detailed comparison among developers' willingness and preference for policies in different areas. In this way, a more specific government policy could be proposed in different areas and countries.

\section{References}

Abidin, N. Z. 2010. Investigating the awareness and application of sustainable construction concept by Malaysian developers, Habitat International 34(4): 421-426.

https://doi.org/10.1016/j.habitatint.2009.11.011

Ajzen, I. 1985. From intentions to actions: A theory of planned behavior. New York, NY: Springer Berlin Heidelberg.

Ajzen, I. 2011. The theory of planned behaviour: Reactions and reflections, Psychology \& Health 26(9): 1113-1127. https://doi.org/10.1080/08870446.2011.613995

Bentler, P. M.; Weeks, D. G. 1980. Linear structural equations with latent variables, Psychometrika 45(3): 289-308. https://doi.org/10.1007/BF02293905

Berens, G.; Riel, C. B. M. V.; Rekom, J. V. 2007. The CSR-quality trade-off: When can corporate social responsibility and corporate ability compensate each other?, Journal of Business Ethics 74(3): 233-252.

https://doi.org/10.1007/s10551-006-9232-0 
Carnoske, C.; Hoehner, C.; Ruthmann, N.; Frank, L.; Handy, S.; Hill, J.; Ryan, S.; Sallis, J.; Glanz, K.; Brownson, R. 2010. Developer and realtor perspectives on factors that influence development, sale, and perceived demand for activity-friendly communities, Journal of Physical Activity \& Health 7: 48-59. https://doi.org/10.1123/jpah.7.s1.s48

Chegut, A.; Eichholtz, P.; Kok, N. 2014. Supply, demand and the value of green buildings, Urban Studies 51(1): 22-43. https://doi.org/10.1177/0042098013484526

China Real Estate Assessment Centre (CREAC). 2017. Comprehensive strength ranking report of developing enterprises in China. Report.

Choi, C. 2009. Removing market barriers to green development: Principles and action projects to promote widespread adoption of green development practices, Journal of Sustainable Real Estate 1: 107-138.

Choi, E. 2010. Green on buildings: The effects of municipal policy on green building designations in America's central cities, Journal of Sustainable Real Estate 2: 1-20.

Deng, Y. H.; Wu, J. 2014. Economic returns to residential green building investment: The developers' perspective, Regional Science and Urban Economics 47: 35-44. https://doi.org/10.1016/j.regsciurbeco.2013.09.015

Eichholtz, P.; Kok, N.; Quigley, J. M. 2010. Doing well by doing good? Green office buildings, American Economic Review 100(5): 2492-2509. https://doi.org/10.1257/aer.100.5.2492

Elias, E. M.; Lin, C. K. 2015. The empirical study of green buildings (residential) implementation: perspective of house developers, Procedia Environmental Sciences 28: 708-716. https://doi.org/10.1016/j.proenv.2015.07.083

Gabay, H.; Meir, I. A.; Schwartz, M.; Werzberger, E. 2014. Costbenefit analysis of green buildings: An Israeli office buildings case study, Energy and Buildings 76: 558-564. https://doi.org/10.1016/j.enbuild.2014.02.027

Gou, Z.; Prasad, D.; Lau, S. S. Y. 2013. Are green buildings more satisfactory and comfortable?, Habitat International 39: 156161. https://doi.org/10.1016/j.habitatint.2012.12.007

Gulen, H.; Ion, M. 2016. Policy uncertainty and corporate investment, The Review of Financial Studies 29(3): 523-564.

He, C.; Han, Q.; Bauke, V. D.; Zhao, G. 2017. Evaluation of sustainable land management in urban area: A case study of Shanghai, China, Ecological Indicators 80: 106-113. https://doi.org/10.1016/j.ecolind.2017.05.008

Hui, E. C. M.; Liang, C.; Wang, Z. Y.; Wang, Y. 2016. The roles of developer's status and competitive intensity in presale pricing in a residential market: A study of the spatio-temporal model in Hangzhou, China, Urban Studies 53(6): 1203-1224. https://doi.org/10.1177/0042098015572317

Hwang, B. G.; Tan, J. S. 2012. Green building project management: obstacles and solutions for sustainable development, Sustainable Development 20(5): 335-349. https://doi.org/10.1002/sd.492

Kline, R.. 2016. Principles and practices of structural equation modeling. New York, NY: The Guilford Press.

Li, Y. Y.; Chen, P. H.; Chew, D. A. S.; Teo, C. C. 2014. Exploration of critical resources and capabilities of design firms for delivering green building projects: Empirical studies in Singapore, Habitat International 41: 229-235. https://doi.org/10.1016/j.habitatint.2013.08.008

Liu, H.; Li, J.; Sun, Y.; Wang, Y.; Li, W. 2014. Government incentives to promote the development of green building based on games theory, Advanced Materials Research 869-870: 381384.
Liu, R.; Xu, Y. 2015. Comparison of international incentive policy of green building, in Proceedings of the $5^{\text {th }}$ International Asia Conference on Industrial Engineering and Management Innovation (Iemi2014), 21 July 2015, Xi'an, China, 319-323. https://doi.org/10.2991/978-94-6239-100-0_58

Ma, H.; Wang, J. 2012. Green dwelling's driving model based on multi-factor analysis, Science and Technology Management Research 6: 226-231.

Matisoff, D. C.; Noonan, D. S.; Flowers, M. E. 2016. Green buildings: Economics and policies, Review of Environmental Economics and Policy 10(2): 329-346.

https://doi.org/10.1093/reep/rew009

Olubunmi, O. A.; Xia, P. B.; Skitmore, M. 2016. Green building incentives: A review, Renewable \& Sustainable Energy Reviews 59: 1611-1621. https://doi.org/10.1016/j.rser.2016.01.028

Patel, C.; Chugan, P. K. 2013. Measuring awareness and preferences of real estate developers for green buildings over conventional buildings, in J. Aagja, A. K. Awasthi, S. Jain (Eds.). Consumer behaviour and emerging practices in marketing. Mumbai: Institute of Management, Nirma University, Himalaya Publishing House, 332-341.

Porter, M. E.; Kramer, M. R. 2006. The link between competitive advanyage and corporate social responsibility, Harvard Business Review 84(12): 78-92.

Prakash, A. 2000. Greening the firm: The politics of corporate environmentalism. Cambridge: Cambridge University Press. https://doi.org/10.1017/CBO9780511491863

Qian, Q. K.; Chan, E. H. W.; Khalid, A. 2015. Challenges in delivering green building projects: Unearthing the transaction costs (TCs), Sustainability 7(4): 3615-3636.

https://doi.org/10.3390/su7043615

Sentman, S. D.; Percio, S. T. D.; Koerner, P. 2008. A climate for change: Green building policies, programs, and incentives, Journal of Green Building 3(2): 46-63.

https://doi.org/10.3992/jgb.3.2.46

Sert, N. Y. 2012. Benefit perception about the understanding of corporate social responsibility in private sector in Turkey: Using web sites for announcing of corporate social responsibility activities, AJIT-e: Online Academic Journal of Information Technology 3(9): 23-34.

Shapiro, S. 2011. Code green: Is "greening" the building code the best approach to create a sustainable built environment?, Planning \& Environmental Law 63(6): 3-12. https://doi.org/10.1080/15480755.2011.586282

Shazmin, S. A. A.; Sipan, I.; Sapri, M. 2016. Property tax assessment incentives for green building: A review, Renewable \& Sustainable Energy Reviews 60: 536-548. https://doi.org/10.1016/j.rser.2016.01.081

Sweeney, J. 2006. How to measure corporate social responsibility, Eureka Street 16(6): 23-24.

Theunissen, R. 2016. Green building strategy, investment and change in the South African real estate industry. Pretoria: University of Pretoria.

Timperley, S. 2008. Corporate social responsibility indexes: Measure for measure. Hamilton: University of Waikato.

USEIA. 2010. International energy outlook 2010. U.S. Energy Information Administration, Office of Integrated Analysis and Forecasting, U.S. Department of Energy, Washington, DC.

Wang, X.; Liu, Y. 2014. Market dynamics and empirical analysis of developing green dwellings, Systems Engineering - Theory \& Practice 34(9): 2274-2281.

Wang, X. W.; Liu, Y. S.; Hou, J. 2015. Strategy selection of supply chain management of green building based on govern- 
ment subsidies and consumers' environmental preferences, in Proceedings of $3^{\text {rd }}$ International Conference on Logistics, Informatics and Service Science, 20 August 2015, Reading, UK, 717-722.

https://doi.org/10.1007/978-3-642-40660-7_107

Weston, R.; Gore, P. A., Jr. 2006. A brief guide to structural equation modeling, Counseling Psychologist 34(5): 719-751. https://doi.org/10.1177/0011000006286345

Windapo, A. O. 2014. Examination of green building drivers in the South African construction industry: Economics versus ecology, Sustainability 6(9): 6088-6106.

https://doi.org/10.3390/su6096088

Wu, S. I.; Wu, Y. C. 2014. The influence of enterprisers' green management awareness on green management strategy and organizational performance, International Journal of Quality \& Reliability Management 31(4): 455-476. https://doi.org/10.1108/IJQRM-01-2013-0019

Wymer, W.; Polonsky, M. J. 2015. The limitations and potentialities of green marketing, Journal of Nonprofit \& Public Sector Marketing 27(3): 239-262.

https://doi.org/10.1080/10495142.2015.1053341

Xu, J.-z.; Qiu, E.-w. 2006. Green corporate culture, Commercial Research 10.

Xu, J.; Wang, Y.; Tao, Z. 2013. Rough approximation based strategy model between a green building developer and a contractor under a fuzzy environment, Knowledge-Based Systems 46: 54-68. https://doi.org/10.1016/j.knosys.2013.03.002

Yi, H.; Liu, Y. 2015. Green economy in China: Regional variations and policy drivers, Global Environmental Change 31: 11-19. https://doi.org/10.1016/j.gloenvcha.2014.12.001

Zhang, L.; Liu, H. 2013. A quantitative analysis of the premium of green residential market in China, Journal of Engineering Management 6: 107-111.

Zhang, X. 2015. Green real estate development in China: State of art and prospect agenda - A review, Renewable and Sustainable Energy Reviews 47: 1-13. https://doi.org/10.1016/j.rser.2015.03.012

Zhang, X. L.; Shen, L. Y.; Wu, Y. Z. 2011. Green strategy for gaining competitive advantage in housing development: a China study, Journal of Cleaner Production 19(2-3): 157-167. https://doi.org/10.1016/j.jclepro.2010.08.005

Zheng, S. Q.; Wu, J.; Kahn, M. E.; Deng, Y. H. 2012. The nascent market for "green" real estate in Beijing, European Economic Review 56(5): 974-984.

https://doi.org/10.1016/j.euroecorev.2012.02.012

Zhou, Y. 2015. State power and environmental initiatives in China: Analyzing China's green building program through an ecological modernization perspective, Geoforum 61: 1-12. https://doi.org/10.1016/j.geoforum.2015.02.002

Zuo, J.; Zhao, Z. Y. 2014. Green building research-current status and future agenda: A review, Renewable \& Sustainable Energy Reviews 30: 271-281.

https://doi.org/10.1016/j.rser.2013.10.021 